\title{
Activation of neural cholecystokinin-1 receptors induces relaxation of the isolated rat duodenum which is reduced by nitric oxide synthase inhibitors
}

S.R. Martins ${ }^{1}$, R.B. de Oliveira ${ }^{1}$ and G. Ballejo ${ }^{2}$

\author{
1Departamento de Clinica Médica, ${ }^{2}$ Departamento de Farmacologia, \\ Faculdade de Medicina de Ribeirão Preto, Universidade de São Paulo, \\ Ribeirão Preto, SP, Brasil
}

Correspondence

G. Ballejo

Departamento de Farmacologia

FMRP, USP

14049-900 Ribeirão Preto, SP

Brasil

Fax: +55-16-3633-2301

E-mail: gboliver@fmrp.usp.br

Publication supported by FAPESP.

$\ldots \ldots \ldots \ldots \ldots \ldots \ldots$

Received February 28, 2005

Accepted October 6, 2005

\begin{abstract}
Cholecystokinin (CCK) influences gastrointestinal motility, by acting on central and peripheral receptors. The aim of the present study was to determine whether CCK has any effect on isolated duodenum longitudinal muscle activity and to characterize the mechanisms involved. Isolated segments of the rat proximal duodenum were mounted for the recording of isometric contractions of longitudinal muscle in the presence of atropine and guanethidine. CCK-8S $\left(\mathrm{EC}_{50}\right.$ : 39; $95 \% \mathrm{CI}: 4.1-152 \mathrm{nM}$ ) and cerulein ( $\left.\mathrm{EC}_{50}: 58 ; 95 \% \mathrm{CI}: 18-281 \mathrm{nM}\right)$ induced a concentration-dependent and tetrodotoxin-sensitive relaxation. $\mathrm{N}^{\omega}$ nitro-L-arginine (L-NOARG) reduced CCK-8S- and ceruleininduced relaxation $\left(\mathrm{IC}_{50}: 5.2\right.$; $\left.95 \% \mathrm{CI}: 2.5-18 \mu \mathrm{M}\right)$ in a concentrationdependent manner. The magnitude of $300 \mathrm{nM} \mathrm{CCK}-8 \mathrm{~S}$-induced relaxation was reduced by $100 \mu \mathrm{M}$ L-NOARG from $73 \pm 5.1$ to $19 \pm 3.5 \%$ in an L-arginine but not D-arginine preventable manner. The CCK-1 receptor antagonists proglumide, lorglumide and devazepide, but not the CCK-2 receptor antagonist L-365,260, antagonized CCK-8Sinduced relaxation in a concentration-dependent manner. These findings suggest that CCK-8S and cerulein activate intrinsic nitrergic nerves acting on CCK-1 receptors in order to cause relaxation of the rat duodenum longitudinal muscle.
\end{abstract}

Key words

- CCK

- CCK receptor subtype 1

- Proximal duodenum

- Myenteric neurons

- Nitric oxide

\section{Introduction}

Cholecystokinin (CCK) is produced and released by endocrine cells of the duodenal mucosa as well as by central and peripheral neurons including some primary afferent neurons innervating the gastrointestinal tract (1). Considerable evidence has accumulated indicating that $\mathrm{CCK}$, in addition to exerting its well-known effects on pancreatic exo- crine secretion, also regulates gastrointestinal motility (2-4). CCK interacts with two distinct receptors, type A or type B (5), now denominated type 1 and type 2 (6). Both receptor types have been implicated in the excitatory and inhibitory motor effects of CCK on the various regions of the gastrointestinal tract including the lower esophageal sphincter, pyloric muscle and small intestine (7-9). Although the presence of CCK recep- 
tors in enteric neurons has been inferred from pharmacological studies and electrophysiological observations $(10,11)$ and more recently from immunohistochemical studies of c-fos induction $(12,13)$, direct evidence for the presence of CCK-A (type 1) receptors in rat myenteric neurons has been provided only recently $(14,15)$. It has been suggested that CCK inhibits canine intestinal circular muscle through the activation of enteric nitrergic and/or vasoactive intestinal peptide-containing neurons (2). Therefore, the objectives of the present study were to determine whether CCK and cerulein, a CCK receptor agonist derived from frog skin, have any influence on isolated rat duodenal longitudinal muscle contractility and to characterize the sites of their action as well as the mechanisms involved.

\section{Material and Methods}

All procedures were conducted according to the local Ethics Guidelines for Animal Experimentation (Comissão de Ética em Experimentação Animal, Faculdade de Medicina de Ribeirão Preto, Universidade de São Paulo) based on international guidelines of animal care and all efforts were made to minimize the number of animals used and their suffering. Male Wistar rats weighing 250-300 g were exsanguinated by section of the cervical vessels and a $2.0-$ to $2.5-\mathrm{cm}$ long whole segment of the proximal portion of the duodenum was removed. The segments were mounted for the recording of the activity of longitudinal muscle under $2 \mathrm{~g}$ of resting tension in a $10-\mathrm{mL}$ organ bath containing $\mathrm{Ca}^{2+}$-free Tyrode solution $(137 \mathrm{NaCl}$, $3 \mathrm{mM} \mathrm{KCl}, 1 \mathrm{mM} \mathrm{MgCl} 2,12 \mathrm{mM} \mathrm{NaHCO}_{3}$, $0.4 \mathrm{mM} \mathrm{NaHPO}$, and $11.1 \mathrm{mM}$ glucose) maintained at $32^{\circ} \mathrm{C}$ and continuously bubbled with air. Longitudinal muscle tension was recorded polygraphically with a HewlettPackard 7754A polygraph (Palo Alto, CA, USA) by means of an isometric force transducer (FTA 10) as described (16). The duode- nal segments were washed every $15 \mathrm{~min}$ for up to $120 \mathrm{~min}$ with $\mathrm{Ca}^{2+}$-free Tyrode solution. Tension was then induced by adding $\mathrm{CaCl}_{2}$ to the bath (1 mM final concentration). Under these conditions the tonus induced was stable and the spontaneous activity was of low amplitude. Because gastrointestinal motility inhibition is mediated mainly by nonadrenergic, noncholinergic neural mechanisms the effect of two CCK receptor agonists, CCK-8S and cerulein, was determined in the presence of $1 \mu \mathrm{M}$ atropine and $3 \mu \mathrm{M}$ guanethidine. Electrical field stimulation was applied through two ring platinum electrodes placed immediately above and below the duodenal segment, and consisted of square wave pulses $(32 \mathrm{~V}, 0.5 \mathrm{~ms}$, 1-8.0 Hz) applied for $10 \mathrm{~s}$ at 2- to 3-min intervals. Cerulein and CCK-8S concentration response curves were constructed by the non-cumulative method with 30-min intervals between each addition in order to prevent tachyphylaxis. The effect of the different inhibitors was determined in the same preparation after obtaining consistent control responses. Separate preparations were employed for testing tetrodotoxin (TTX), $\mathrm{N}^{\omega}$ nitro-L-arginine (L-NOARG) and each of the antagonists, which were incubated for at least 20 min before adding $\mathrm{Ca}^{2+}$ to raise the tension of the preparation.

\section{Drugs}

Cerulein, CCK-8S, TTX, atropine sulfate, guanethidine, L-NOARG, L-arginine (L-ARG), D-arginine (D-ARG), proglumide, and lorglumide were obtained from Sigma/ RBI (St. Louis, MO, USA). Devazepide (L364,718) and L-365,260 were from Merck \& Co., Rahway, NJ, USA. Concentrated stock solutions of all drugs were prepared in distilled water except lorglumide, devazepide and L-365,260 which were dissolved in methanol. The amount of methanol added to the organ bath never exceeded $0.1 \%$ of the total volume. Drug- or nerve-elicited re- 
sponses were not affected by the presence of this amount of methanol.

\section{Statistical analysis}

The $\mathrm{EC}_{50}$ values were calculated after logit-log transformation of the data and are reported as the geometric mean and $95 \%$ confidence intervals (95\% CI). Relaxation is reported as percent reduction in tension or as percent of the control value obtained before adding the antagonists and is reported as mean \pm SEM. Statistical significance was determined by the Student $t$-test for paired samples, with the level of significance set at $\mathrm{P}<0.05$.

\section{Results}

Cerulein caused an initial rapid decrease in tension of the longitudinal muscle of the rat proximal duodenum followed by an increase in tension above the initial tonus; this biphasic response elicited by cerulein was abolished by $1 \mu \mathrm{M}$ TTX, which also abolished electrical field stimulation-elicited responses (Figure 1A). Similar findings were observed with CCK-8S (data not shown). The magnitude of relaxation increased with the concentration of both agonists (Figure $1 \mathrm{~B})$ and the potency of CCK-8S $\left(\mathrm{EC}_{50}: 39\right.$; 95\% CI: 4.1-152 nM) was slightly higher but not statistically different from that of cerulein $\left(\mathrm{EC}_{50}: 58 ; 95 \% \mathrm{CI}: 18-281 \mathrm{nM}\right)$.

The selective CCK-1 receptor antagonists proglumide, lorglumide and devazepide, but not the CCK-2 receptor antagonist L365,260 , reduced the magnitude of $330 \mathrm{nM}$ CCK-8S-induced relaxations in a concentration-dependent manner but had no effect, or even magnified the excitatory response (Figure 2).

The magnitude of $300 \mathrm{nM} \mathrm{CCK-8S-and}$ cerulein- (data not shown) elicited relaxation was reduced by L-NOARG in a concentration-dependent manner $\left(\mathrm{IC}_{50}: 5.2 ; 95 \%\right.$ CI: 2.5-18 $\mu \mathrm{M})$. L-ARG (1 mM), but not D-
A
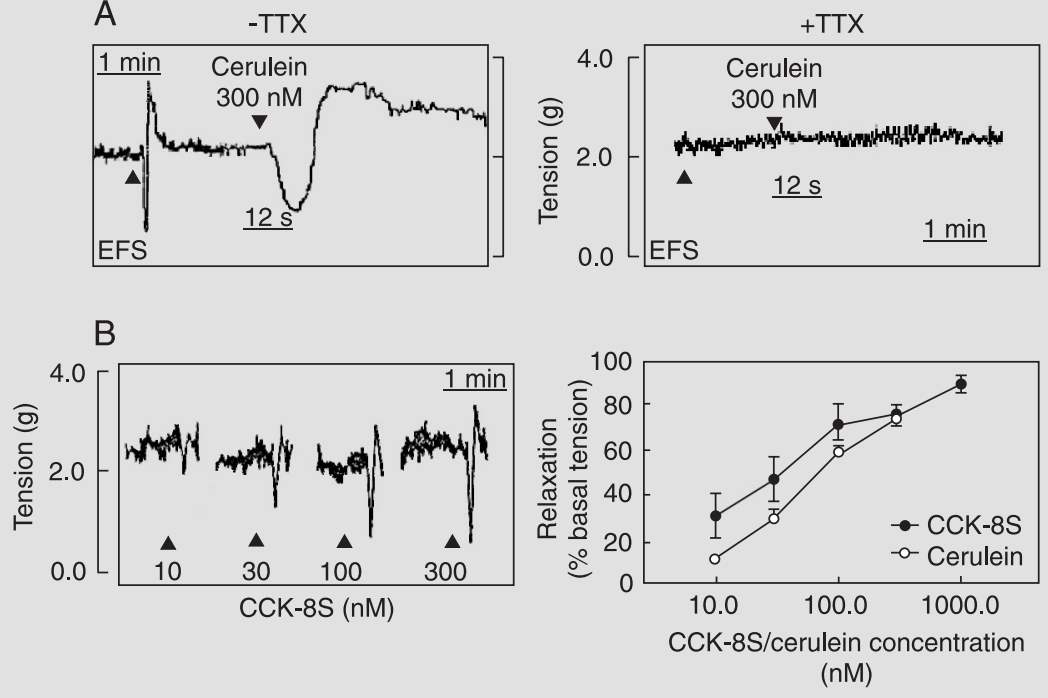

Figure 1. A, Representative tracings showing the effects of EFS (triangles) and cerulein (inverted triangles) on the tension of longitudinal muscle of rat duodenum in the absence (left) and in the presence (right) of $1 \mu \mathrm{M}$ tetrodotoxin (TTX). B, Left, Responses of rat duodenum longitudinal muscle induced by different concentrations of CCK-8S. The interval between the additions to the bath was $30 \mathrm{~min}$. Right, Relationship between CCK-8S and cerulein concentrations and the magnitude of the relaxations of rat duodenum longitudinal muscle. Data are reported as the means \pm SEM for 4-6 experiments. EFS $=$ electrical field stimulation; CCK-8S = cholecystokinin-8S.

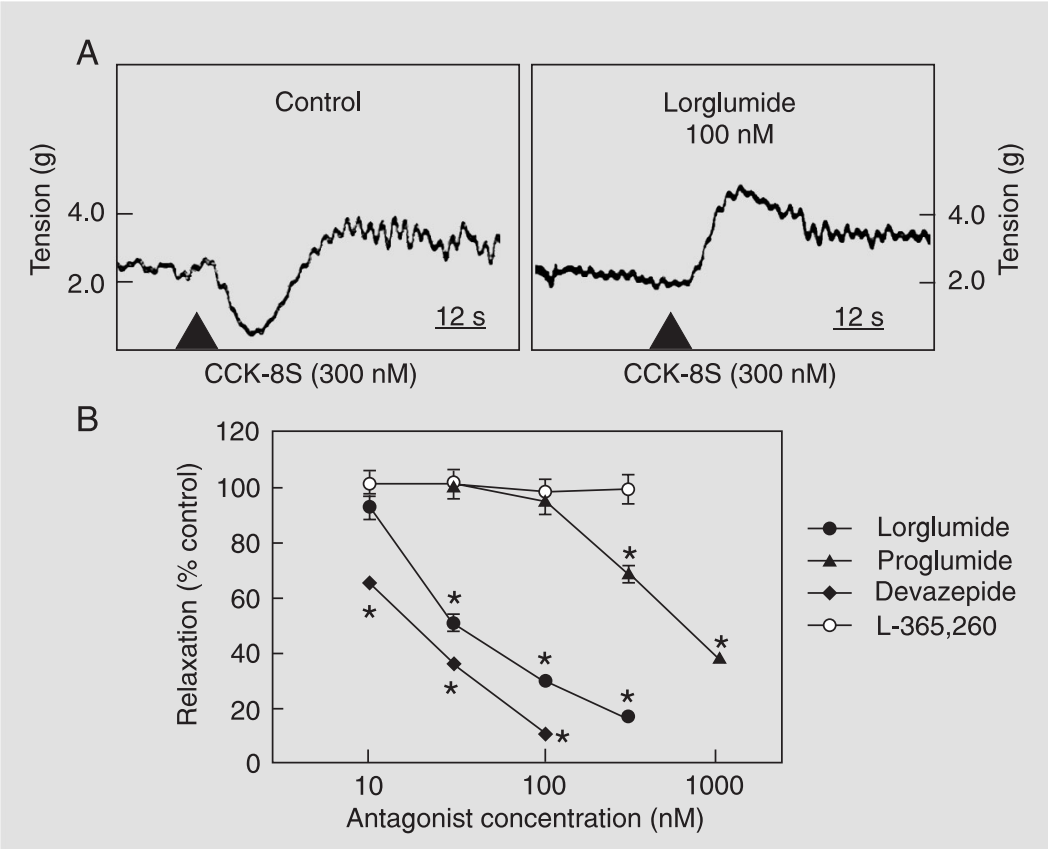

Figure 2. A, Representative tracings showing the effect of $300 \mathrm{mM} \mathrm{CCK}-8 \mathrm{~S}$ on the tension of rat duodenum longitudinal muscle in the absence (left, control) and in the presence (right) of $100 \mathrm{nM}$ lorglumide. B, Concentration dependence of different CCK antagonists on the magnitude of CCK-8S-induced relaxation of the rat duodenum longitudinal muscle. Data are reported as the means \pm SEM for 6-8 experiments. CCK-8S $=$ cholecystokinin- $8 S$. ${ }^{*} \mathrm{P}<$ 0.05 compared to control responses (paired Student $t$-test). 
ARG (1 mM), prevented the reduction of CCK-8S-induced relaxation caused by 100 $\mu \mathrm{M}$ L-NOARG (Figure 3).

\section{Discussion}

The present study shows that CCK-8S and cerulein cause an initial relaxation followed by contraction of the isolated longitudinal muscle of the rat proximal duodenum. Both the excitatory and inhibitory actions of CCK on gastrointestinal motility have been previously described in intact dogs (2) and rats $(3,4)$. The fact that in the present experiments both effects were abolished by TTX indicates that they are mediated by the activation of neural structures located in the duodenal wall. Although it has been reported that the in vitro contractile effect of CCK on gastrointestinal muscle is mediated in part by a presynaptic action of CCK involving the release of $\mathrm{ACh}$ from cholinergic intrinsic nerves (17), it is worth noting that the contractile response in our experiments was observed in the presence of atropine. Therefore, and in contrast with the findings in canine gastrointestinal tract $(18,19)$, it is unlikely that the neural-dependent contractile effect of CCK on the longitudinal muscle of the rat proximal duodenum involves the activation of muscarinic receptors. Rather, this TTX-sensitive contraction probably depends on the release of substance $\mathrm{P}$ from

Figure 3. Effect of $100 \mu \mathrm{M} \mathrm{L-}$ NOARG on the magnitude of $300 \mathrm{nM}$ CCK-8S-induced relaxation of rat duodenum longitudinal muscle in the absence and in the presence of $\mathrm{L}$-arginine ( $\mathrm{L}$ ARG, $1 \mathrm{mM}$ ), or D-arginine (DARG, $1 \mathrm{mM}$ ). Data are reported as the means \pm SEM for 4-6 experiments. $\mathrm{L}-\mathrm{NOARG}=\mathrm{N}^{\omega}$ nitroL-arginine; CCK-8S = cholecystokinin-8S. ${ }^{*} \mathrm{P}<0.05$ compared to the control response (paired Student $t$-test).

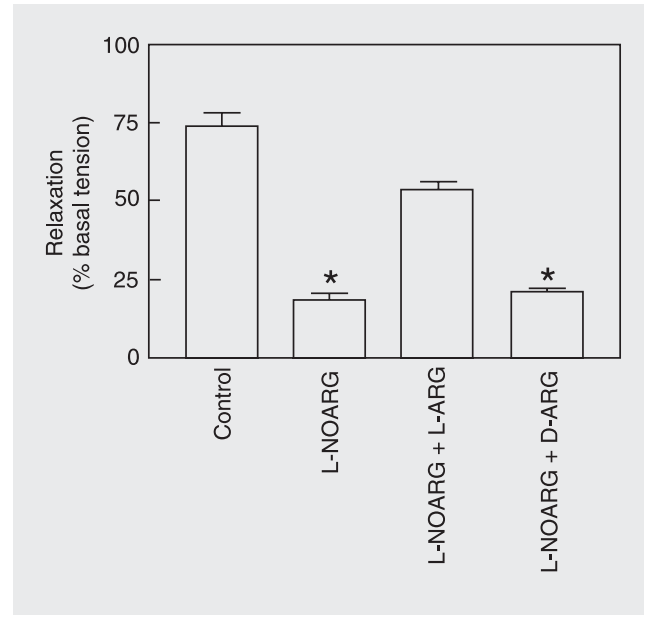

intrinsic nerves, as observed in the longitudinal muscle of the guinea pig ileum (20). Interestingly, CCK-1 receptors have been recently detected in a subpopulation of substance P-containing myenteric neurons, which is consistent with the possibility that the contractile effect of CCK-8S may involve release of substance P. However, since CCK-1 receptor antagonists did not affect the contractile response and even enhanced it, it is likely that CCK receptors other than types 1 or 2 are present in excitatory noncholinergic neural structures of the duodenal wall. Interestingly, a non-A non-B CCK receptor has been postulated to mediate the activation of primary gastric vagal afferents in OLETF rats that lack CCK-1 receptors (21).

Since the relaxation induced by CCK-8S and cerulein was also abolished by TTX we focused our experiments on the pharmacological characterization of the receptors and of the mediators involved in such effect. The fact that three selective CCK-1 receptor antagonists were able to reduce the magnitude of CCK-8S (and cerulein)-elicited relaxation in a concentration-dependent manner indicates that these responses are mediated predominantly by the activation of CCK-1 receptors. These receptors may be located either in nonadrenergic noncholinergic inhibitory neurons or in interstitial cells of Cajal since CCK-1 receptor immunoreactivity has been recently described in both cell types in the rat intestine $(14,15)$. It is noteworthy that interstitial cells of Cajal have been postulated to mediate neurally induced relaxation in mice (22). The experimental design of the present study does not allow us to identify which of these cells is responsible for the observed effect. However, it is most likely that CCK-8S is acting directly on neurons since recent gene expression studies in the rat have shown that duodenal myenteric neurons express nuclear c-fos after ip CCK administration in a devazepide-sensitive manner (12). This interpretation is also consistent with the results of electrophysiological 
studies in guinea pig myenteric neurons (11). Furthermore, the fact that L-NOARG was able to reduce the magnitude of the relaxation elicited by CCK-8S in an L-ARGpreventable manner indicates that they are mediated mainly by myenteric nitrergic neurons. These neurons have been previously shown to be present in the myenteric plexus of the proximal rat duodenum and contribute to nonadrenergic noncholinergic nerve-mediated relaxation of this intestinal segment $(16,23)$. This interpretation is consistent with the recent observation that c-fos is induced in duodenal myenteric neurons expressing nitric oxide synthase after ip $\mathrm{CCK}$ administration to rats (13).

The present study showed that CCK-8S acting on CCK-1 receptors relaxes the longitudinal muscle of the rat proximal duodenum through the activation of intrinsic nitrergic neurons. Whether these CCK-1 receptors are located exclusively on the neurons or in the interstitial cells of Cajal remains to be further investigated.

\section{References}

1. Walsh JH (1994). Gastrointestinal hormones. In: Johnson LR (Editor), Physiology of the Gastrointestinal Tract. Chapter 1. 3rd edn. Raven Press, New York, 1-128.

2. Vergara P, Woskowska Z, Cipris S et al. (1996). Mechanisms of action of cholecystokinin in the canine gastrointestinal tract: role of vasoactive intestinal peptide and nitric oxide. Journal of Pharmacology and Experimental Therapeutics, 279: 306-316.

3. Takahashi T \& Owyang C (1999). Mechanism of cholecystokinininduced relaxation of the rat stomach. Journal of the Autonomic Nervous System, 75: 123-130.

4. Giralt M \& Vergara P (1999). Both afferent and efferent nerves are implicated in cholecystokinin motor actions in the small intestine of the rat. Regulatory Peptides, 81: 73-80.

5. Wank AS (1998). Protein coupled receptors in gastrointestinal physiology. I. CCK receptors: an exemplary family. American Journal of Physiology, 274: G607-G613.

6. Noble F, Wank AS, Crawley JN et al. (1999). International Union of Pharmacology XXI. Structure, distribution and functions of cholecystokinin receptors. Pharmacological Reviews, 51: 745-781.

7. Giuliani S, Lippe IT, Maggi CA et al. (1990). Dual effects of cholecystokinin octapeptide on duodenal motility of urethane anesthetized rats. Journal of Pharmacology and Experimental Therapeutics, 252: 1312-1317.

8. Salapatek A, Hynna-Liepert T \& Daimant N (1992). Mechanism of action of cholecystokinin octapeptide on the cat lower esophageal sphincter. American Journal of Physiology, 263: G419-G425.

9. Rodríguez-Membrillo A, Martinez V \& Vergara P (1995). Peripheral and central CCK receptors regulate post-prandial intestinal motility in the rat. Journal of Pharmacology and Experimental Therapeutics, 275: 489-493.

10. Grider JR (1994). Role of cholecystokinin in the regulation of gastrointestinal motility. Journal of Nutrition, 124: 1334S-1339S.

11. Schutte IWM, Hollestein KBCW, Akkermans LMA et al. (1997). Evidence for a role of cholecystokinin as neurotransmitter in the guinea-pig enteric nervous system. Neuroscience Letters, 236: 155158.

12. Sayegh Al \& Ritter RC (2000). CCK-A receptor activation induces Fos expression in myenteric neurons of rat small intestine. Regulatory Peptides, 88: 75-81.
13. Sayegh Al \& Ritter RC (2003). Cholecystokinin activates specific enteric neurons in the rat small intestine. Peptides, 24: 237-244.

14. Sternini C, Wong H, Pham T et al. (1999). Expression of cholecystokinin A receptors in neurons innervating rat stomach and intestine. Gastroenterology, 117: 1136-1146.

15. Patterson LM, Zheng H, Ward SM et al. (2001). Immunohistochemical identification of cholecystokinin A receptors on interstitial cells of Cajal, smooth muscle and enteric neurons in rat pylorus. Cell and Tissue Research, 305: 11-23.

16. Martins SR, Bicudo R, Oliveira RB et al. (1993). Evidence for the participation of the L-arginine-nitric oxide pathway in neurally induced relaxation of the isolated rat duodenum. Brazilian Journal of Medical and Biological Research, 26: 1325-1335.

17. Bertaccini G (1982). Peptides and gastrointestinal hormones. In: Bertaccini G (Editor), Handbook of Experimental Pharmacology. Vol. 59, Part II, Chapter 2a. Springer-Verlag, Berlin, Germany, 1182.

18. Fox JE, Daniel EE, Jury J et al. (1983). Sites and mechanism of action of neuropeptides on canine gastric motility differ in vivo and in vitro. Life Sciences, 33: 817-825.

19. Allescher HD, Daniel EE, Fox JET et al. (1989). Effect of the novel CCK receptor antagonist CR-1392 on cholecystokinin-induced antroduodenal and pyloric motor activity in vivo. Journal of Pharmacology and Experimental Therapeutics, 251: 1134-1141.

20. Hutchinson JB \& Dockray GJ (1981). Evidence that the action of cholecystokinin octapeptide on the guinea pig ileum longitudinal muscle is mediated in part by substance $P$ release from the myenteric plexus. European Journal of Pharmacology, 69: 87-93.

21. Kurosawa M, Bucinskaite V, Taniguchi T et al. (1999). Response of the gastric vagal afferent activity to cholecystokinin in rats lacking type A cholecystokinin receptors. Journal of the Autonomic Nervous System, 75: 51-59.

22. Burns AJ, Lomax AE, Torihashi S et al. (1996). Interstitial cells of Cajal mediate inhibitory neurotransmission in the stomach. Proceedings of the National Academy of Sciences, USA, 93: 1200812013.

23. Postorino A, Serio R \& Mule F (1995). Nitric oxide is involved in nonadrenergic, non-cholinergic inhibitory neurotransmission in rat duodenum. Journal of Autonomic Pharmacology, 15: 65-71. 